\title{
O turismo de base comunitária em tempos de pandemia: Experiências de comunidades do Brasil e da África
}

\section{Community-based tourism during pandemics: Experiences of communities in Brazil and Africa}

\author{
Eduardo de Ávila Coelho \\ Universidade Federal de Minas Gerais, Brasil \\ eduardo.coelho@meioambiente.mg.gov.br
}

\begin{abstract}
Resumo
O novo coronavírus se espalhou pelo planeta em 2020, causando graves crises de consequências sanitárias, econômicas e políticas. Muitas atividades não essenciais foram paralisadas, dentre elas, o turismo. Algumas comunidades turísticas estão sendo duplamente afetadas: pela paralisação de suas atividades econômicas e pela ameaça de o vírus alcançar suas regiões. Este trabalho analisa a relação entre a COVID-19 e o turismo de base comunitária, utilizando para a análise a bibliografia referente aos temas e considerando exemplos de comunidades que enfrentam o momento de crise. Para auxiliar na compreensão dos desafios enfrentados, foram realizadas entrevistas com lideranças comunitárias do Brasil e da África. Os relatos demonstram que os moradores sentem a falta de apoio dos governos, que culmina com a falta de renda e o medo em receber turistas. Enquanto isso, se preparam, em meio às incertezas, para as novas formas de prestar serviços.
\end{abstract}

Palavras-chave: Turismo de base comunitária; COVID-19; pandemia; saúde; viagens.

\begin{abstract}
The new coronavirus spread across the planet in 2020 causing severe crises with sanitary, economic and political consequences. Due to containment measures, many non-essential activities were paralyzed, including tourism. Some touristic communities are being doubly affected by the pandemic, due to the paralysis of their economic activities, while the threat of the virus reaches their regions. This article aims to analyse the relationship between community-based tourism and COVID-19, using the bibliography referring to both themes and showing examples from communities that are facing the moment of crisis. In order to contextualize the challenges faced by local actors, interviews were made with community leaders from Brazil and Africa. Results show that residents feel the absence of support from governments, which culminates in the lack of income and the fear of hosting tourists. Meanwhile, they are preparing, in the midst of uncertainties, for new ways of providing services.
\end{abstract}

Keywords: Community-based tourism; COVID-19; pandemics; health; travel.

Dos Algarves: A Multidisciplinary e-Journal, 40-2021.

ISBN 2182-5580 @ ESGHT - University of the Algarve, Portugal.

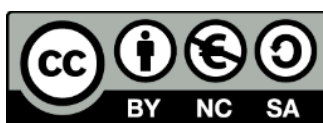

To cite this article: Coelho, E. (2021). Planejamento público e gerenciamento de crises na pandemia da Covid-19 em destinos turísticos no Brasil: Ações sustentáveis ou reações econômicas? Dos Algarves: A Multidisciplinary eJournal, 40, 48-62. DOI: 10.18089/DAMeJ.2021.40.3 


\section{Introdução}

Enquanto este artigo era elaborado, ${ }^{1}$ o mundo continuava enfrentando grandes dificuldades associadas ao controle da pandemia do novo coronavirus disease 2019 (COVID-19). Seguindo a tendência de elevado contágio (enquanto as primeiras vacinas começavam a ser aplicadas em massa), no primeiro semestre de 2021 os números globais já superavam a marca de 180 milhões de infectados e quase 4 milhões de mortes (Worldometers, 23/06/2021). Neste cenário, algumas nações das Américas, Europa e Ásia se destacavam pelos altos índices de transmissão da doença, sendo os Estados Unidos e o Brasil os dois países com maior número de vítimas fatais.

Com a drástica redução nas viagens aéreas internacionais como resultado da crise, e muitas nações impondo proibições de viagens, fechando fronteiras ou introduzindo períodos de quarentena, o turismo doméstico e internacional declinou vertiginosamente durante meses (Gössling et al., 2021). Segundo os autores, a atual situação é inédita e existem evidências de que a COVID-19 será transformadora para o setor de turismo (Gössling et al., 2021), pois crises associadas a pandemias têm efeitos negativos duradouros para a economia e o turismo (Skare et al., 2021). O mundo pós-coronavírus será diferente de muitas maneiras (Sharfuddin, 2020) e, enquanto a realidade atual pode incentivar as pessoas a transformar seus comportamentos de viagem, a transformação do sistema de turismo, no entanto, é extremamente difícil (Hall et al., 2020).

Nesse contexto, o turismo de base comunitária (TBC) também se viu muito afetado pela pandemia. O TBC é um modelo, ou uma segmentação do turismo que está estritamente ligado ao envolvimento direto de comunidades locais na gestão e organização da atividade turística. Espalhadas pelo mundo, cada vez mais, surgem exemplos de comunidades indígenas, tradicionais, em áreas urbanas ou rurais, isoladas em ilhas ou no interior das florestas (Stronza \& Durham, 2008; Bartholo et al., 2009; Salazar, 2012; Coelho, 2013), que vêm trabalhando o turismo como uma forma alternativa de acesso ao mercado e de empoderamento local para a conquista de direitos. Como o restante da população, os membros das comunidades que trabalham com o turismo também estão sujeitos aos riscos do contágio e sofrem com as graves consequências econômicas pela paralisação de suas atividades.

\section{Objetivos e metodologia}

Este trabalho analisa a interface entre o turismo e o novo coronavírus, buscando revelar algumas realidades enfrentadas por comunidades que desenvolvem a atividade em seus territórios. O objetivo é discutir sobre a vulnerabilidade das populações que trabalham com o turismo de base comunitária em momentos de pandemia, apresentando relatos de moradores de diversas comunidades em diferentes partes do Brasil e da África. Para isso, a análise foca nas realidades enfrentadas pelos sujeitos e nas suas percepções sobre as consequências da pandemia. Muitas dessas localidades se encontram em áreas mais remotas

\footnotetext{
${ }^{1}$ A primeira versão deste trabalho foi elaborada e submetida no segundo semestre de 2020 . Os dados sobre números de mortes e contágios foram atualizados antes da submissão da versão final do artigo, em maio de 2021.
} 
e em situação de menor acesso a políticas públicas e a infraestruturas de saúde e saneamento, podendo ou não depender fortemente do turismo. Argumenta-se que o turismo moderno, através das viagens, se tornou o principal vetor de dispersão de doenças contagiosas, devido ao seu extensivo alcance a todas as regiões da Terra, mas sua interrupção repentina pode significar graves desajustes sociais e econômicos para comunidades e famílias, além de ameaçar os empreendimentos locais.

Como método de análise, o artigo se valeu de pesquisa bibliográfica atual sobre a pandemia de COVID-19, e de entrevistas com atores locais selecionados a partir de vivências prévias de campo, ${ }^{2}$ buscando argumentar sobre a influência do turismo em questões como saúde e renda das comunidades receptoras. Compara-se cinco exemplos brasileiros de comunidades do interior da floresta amazônica, do interior de Minas Gerais e da periferia da cidade do Rio de Janeiro. Nos três estados brasileiros já haviam sido conduzidas pesquisas sobre TBC, e o relacionamento prévio permitiu a manutenção do contato com importantes lideranças locais, que responderam a um questionário (via internet) sobre a COVID-19 e o turismo. Da mesma forma, analisam-se dois exemplos da África, em locais também pesquisados anteriormente, onde foram entrevistados (via internet) lideranças locais envolvidas com o turismo em uma comunidade urbana de Maputo, Moçambique e uma comunidade rural no interior de Uganda.

As sete entrevistas realizadas seguiram um roteiro estruturado, com oito perguntas que buscavam compreender a situação enfrentada na região / comunidade e as formas de apoio recebidas, a percepção sobre os riscos do turismo durante a pandemia, as consequências da interrupção da atividade turística e os planos para a adaptação e retorno da atividade. Os entrevistados receberam previamente as perguntas por escrito e posteriormente enviaram suas respostas, por escrito, ou através de aplicativo de áudio. As falas foram analisadas em sua totalidade e então selecionados os trechos que melhor correspondiam às questões levantadas. Os trechos mais relevantes dos relatos dos entrevistados foram copiados e organizados no formato de relato único e contínuo, para cada entrevistado. O diagnóstico buscou apresentar uma análise qualitativa das diferentes realidades enfrentadas por comunidades do Brasil e da África, oportunizando aos agentes locais o espaço para o relato das experiências vividas em um momento de crise que atinge, em diferentes graus, toda a humanidade.

\section{Turismo e COVID-19}

Em momentos de crise sanitária, as populações que desenvolvem o turismo em seus territórios ficam duplamente vulneráveis, pois dependem (em maior ou menor grau) da atividade turística, mas são justamente os turistas e viajantes aqueles que podem estar veiculando as doenças contagiosas surgidas em outras regiões do planeta. É o caso vivido em 2020, com a pandemia do novo coronavírus, que teve seu primeiro caso relatado mundialmente em Wuhan, China, em dezembro de 2019 (Hoque et al., 2020). Em 23 de janeiro, quando o tráfego aéreo foi banido em Wuhan, muitas cidades chinesas já haviam recebido viajantes infectados (Chinazzi et al., 2020). Quando os números se estabilizaram na

2 Desde 2006 o autor vem trabalhando junto a comunidades de diversas regiões do Brasil e, em 2014, em vários países da África. O antigo relacionamento com lideranças locais possibilitou o contato para esta pesquisa. 
China, em meados de fevereiro, o transporte aéreo global já havia levado o vírus para todos os continentes (Gössling et al., 2021). Países como Itália e Espanha foram os primeiros a sofrer grandes impactos fora do continente asiático, já que muitos indivíduos infectados da China continental não foram detectados e potencialmente se dispersaram para destinos internacionais (Chinazzi et al., 2020).

Não demorou muito para que a crise assumisse dimensões planetárias, sendo decretada pandemia em 11 de março pela Organização Mundial da Saúde (OMS/ONU). Apesar de se espalhar por todo o planeta, "essa não é uma única pandemia, mas antes várias experiências de pandemia. Não estamos 'todos juntos nisto"' (Nunes, 2020: 3). O autor afirma que "a vulnerabilidade é uma relação política desigual, por meio da qual determinados grupos [...] são sistematicamente expostos ao empobrecimento, ao adoecimento e à morte" (Nunes, 2020: 3). O desafio para muitos é que o impacto da COVID-19 soma-se aos problemas ambientais, sociais e econômicos previamente enfrentados (Carr, 2020). Para Niewiadomski (2020), desde os processos de descolonização, nenhuma força desafiou de tal forma a globalização - até agora.

A Organização Mundial do Turismo (OMT/ONU) relatou que 100\% dos destinos do mundo sofreram alguma restrição de viagens em resposta à pandemia, com previsões de perdas financeiras mundiais na casa dos trilhões de dólares e ao custo de mais de 100 milhões de empregos (OMT, 2020), e projeções sugerem que a crise está longe do fim para o setor de turismo (Fotiadis et al., 2021). Para Galvani et al. (2020), a pandemia do novo coronavírus é um resultado direto da globalização e foi, em grande parte, devido ao turismo internacional que o vírus se espalhou tão rapidamente por todo o planeta, não sendo surpresa que o turismo se tornou um dos setores econômicos mais atingidos pelos bloqueios e restrições de viagens (Lew et al., 2020).

Os surtos de doenças infecciosas comprometem bastante a indústria do turismo, devido à sua dependência da mobilidade humana (Yang et al., 2020). Os meios de transporte turísticos, como aviões, navios, trens e ônibus auxiliam a propagação de patógenos (Gössling et al., 2021) e a globalização aliada à facilidade de viajar é um fator principal que facilita o surto (Niewiadomski, 2020; Sánchez, 2020). Um passageiro e, portanto, uma doença, podem viajar de um lado a outro do planeta em apenas um dia (Hall et al., 2020), e indícios sugerem que o padrão emergente do surto de COVID-19 seguiu de perto os padrões globais de mobilidade das viagens aéreas de passageiros (Linka et al., 2020).

Restrições às viagens foram amplamente promulgadas em resposta à pandemia, o que em muitos países significou ordens de 'fique em casa' e restrições à circulação (Hall et al., 2020). Os autores concluem que sem mobilidade não há turismo (Hall et al., 2020). As restrições de serviços não essenciais, movimentação e viagens e o fechamento total de locais onde o distanciamento social não era possível fizeram do turismo uma vítima da pandemia (Lapointe, 2020). Enquanto anteriormente o setor estava lidando com preocupações de excesso de turistas, de repente foi empurrado para a beira de um colapso (HigginsDesbiolles, 2020). A escala da COVID-19 abalou a indústria do turismo global com uma força semelhante à Grande Depressão de 1929 ou às duas Guerras Mundiais (Carr, 2020) e despertou a percepção de como nosso mundo realmente está interconectado (TremblayHuet, 2020). A atual pandemia mudou os procedimentos de viagens e, até que uma vacina 
seja encontrada (e aplicada em massa), as respostas de gerenciamento de países e comunidades deverão incluir isolamento, quarentena, distanciamento social, testagem e rastreamento de transmissão (Carr, 2020).

Números da OMT apontam que o turismo apresentava índices crescentes há uma década, desde a crise financeira de 2008-2009, atingindo, em 2019, mais de um bilhão e meio de turistas internacionais (Brouder, 2020). Contudo, a disseminação do coronavírus derrubou de forma drástica este crescimento e o turismo como era há alguns meses deixou de existir (Niewiadomski, 2020). Após ser declarada a pandemia pela OMS, a União Europeia fechou, em 17 de março, todas as suas fronteiras externas pela primeira vez na história, na tentativa de conter a disseminação do vírus (Linka et al., 2020). No início de abril de 2020, a maioria dos países havia fechado suas fronteiras, interrompendo as viagens internacionais por tempo indeterminado e transformando a indústria do turismo de uma maneira nunca vista fora dos períodos de guerra (Prideaux et al., 2020). Os autores dizem que o resultado foi uma interrupção em larga escala dos fluxos de turismo internacional e doméstico, causando uma crise sem paralelos para a indústria global do turismo (Prideaux et al., 2020).

\section{O turismo de base comunitária e a COVID-19}

Como o próprio nome indica, o turismo de base comunitária está intimamente ligado às comunidades locais onde o turismo se desenvolve, e, conforme Salazar (2012), visa criar (pelo menos no discurso) uma indústria do turismo mais sustentável, com foco nas comunidades receptoras em termos de planejamento e manutenção do desenvolvimento do turismo. É uma forma de 'turismo local' que favorece prestadores de serviços e fornecedores locais e tem foco na cultura e no ambiente local (Strydom et al., 2019). Sansolo e Bursztyn (2009) consideram o turismo de base comunitária não como mais um segmento de mercado, mas como a possibilidade de um novo paradigma para o turismo. A condição para esta forma de turismo é o 'encontro' entre identidades, no sentido de compartilhamento e aprendizagem mútua (Irving, 2009). Ideia reiterada por Salazar (2012), ao dizer que o encontro com o 'outro' é central, em uma experiência de contato cultural. Para Maldonado (2009: 31) "a característica distinta do turismo comunitário é sua dimensão humana e cultural, vale dizer antropológica".

Assim, o TBC não deve ser reduzido a uma análise que considere apenas os benefícios econômicos como metas a serem alcançadas (Coelho, 2013). Para Bursztyn et al. (2009: 86), "o turismo de base comunitária, enraizado num processo situado de desenvolvimento, é uma modalidade do turismo sustentável cujo foco principal é o bem-estar e a geração de benefícios para a comunidade receptora". Coriolano (2009: 280) vê "o processo de organização do turismo comunitário como atividade de defesa e de reação ao turismo invasor de comunidades", e assim favorece a coesão e o laço social e o sentido coletivo de vida em sociedade, promovendo a qualidade de vida e o sentimento de pertencimento (Irving, 2009). O TBC contribui para a sobrevivência social e econômica das comunidades marginalizadas nos países em desenvolvimento e a preservação dos recursos naturais nas áreas atingidas (Strydom et al., 2018).

O TBC potencializa modos de vida tradicionais, bem como os arranjos socioprodutivos e políticos de base comunitária (Sampaio \& Coriolano, 2009). Questões como a participação comunitária, a autonomia, o protagonismo e o empoderamento parecem permear grande 
parte dos estudos sobre esta forma de turismo. Muitos tratam também do apoio à conservação da natureza e a implementação de novas práticas conservacionistas (Kiss, 2004), da valorização e manutenção das tradições culturais (Lima \& D'Hauteserre, 2011) e a relação com as lutas sociais (Mendonça \& Irving, 2004). Okazaki (2008) aborda questões relacionadas às formas de participação local, parcerias e redistribuição de poder. Por outro lado, autores como Blackstock (2005) e Lapointe (2020) discutem sobre a contradição entre a retórica do empoderamento e a crescente penetração do capitalismo global, ou sobre a chegada de atores externos e a falta de agência das instituições políticas locais.

Mesmo com virtudes e limitações, esta forma de turismo dispõe de uma capilaridade que a permite alcançar as regiões e comunidades mais distantes (geográfica e culturalmente) do planeta, inserindo-as em modelos de trocas capitalistas e expondo-as a valores e modos de vida distintos. Blackstock (2005) diz que a indústria do turismo está dominando cada vez mais comunidades no mundo e por isso uma abordagem crítica e emancipatória do turismo torna-se essencial. Independentemente dos resultados positivos já alcançados em diversos casos, ou das falhas às formas de implementação da atividade em vários outros, a questão é que as comunidades envolvidas com turismo passaram a ser vulneráveis ao contágio pela COVID-19, por estarem conectadas ao mercado mundial. E, nesse sentido, tornaram-se duplamente vulneráveis, neste momento em que a atividade turística foi paralisada quase por completo. Por uma questão de saúde, devem manter-se isoladas, deixando de receber turistas, enquanto por uma questão econômica, ficam ainda mais desamparadas, podendo perder grande parte da renda e depender do retorno da atividade o mais breve possível. Assim como alertam Wen et al. (2020), a decisão sobre a retomada do turismo deve se basear nas evidências científicas respeitáveis.

O TBC vem se apresentando como opção de desenvolvimento para pequenas comunidades, já que proporciona a ampliação das práticas cotidianas e representa uma nova multifuncionalidade dos espaços rurais (Sansolo \& Bursztyn, 2009). Mas a crise da COVID-19 pode tornar-se ainda mais grave para aquelas comunidades que, por diversas questões, abandonaram (ou reduziram) suas atividades tradicionais anteriormente desenvolvidas, para se dedicarem ao turismo. Na Nova Zelândia, Carr (2020) relata que a pandemia afetou gravemente as empresas e os líderes dos negócios de turismo maori, enquanto na Amazônia brasileira, Peralta (2008) aponta que, mesmo o turismo não tendo sido desenhado para substituir outras atividades econômicas tradicionais, houve uma diminuição da produção da agricultura familiar e muitos membros das comunidades locais passaram a depender da atividade turística como principal fonte de renda, o que se torna ainda mais preocupante em uma situação de suspensão completa da atividade.

Os danos ao turismo causados por uma crise ou desastre podem não apenas ter sérias implicações para uma economia nacional, mas também ameaçar os meios de subsistência de muitas pessoas nos destinos turísticos (Sausmarez, 2007). As restrições de viagens internacionais, regionais e locais afetaram imediatamente as economias nacionais (Gössling et al., 2021) e consequentemente os empreendimentos comunitários. Considerando os destinos que dependem do turismo internacional, a situação é ainda mais grave no caso dos países em desenvolvimento, que são altamente dependentes dos turistas estrangeiros, vindos principalmente dos países desenvolvidos (Romagosa, 2020), os quais foram os 
primeiros a ser afetados de forma drástica, como o caso da Europa, dos EUA e da própria China.

Para Niewiadomski (2020), há diversas evidências de que o crescimento do turismo foi longe demais e seguiu um caminho errado e, neste momento de estagnação, há tempo para reflexão. $O$ autor afirma que a crise criou uma janela excepcional de oportunidade para tornar o turismo mais ambientalmente sustentável, menos explorador e ganancioso e mais respeitoso com as culturas e tradições das comunidades anfitriãs. Segundo Romagosa (2020), as empresas que estão enraizadas no destino e oferecem produtos baseados no patrimônio natural e cultural local, que não contribuem para a superlotação e que propiciam experiências de alta qualidade para turistas com alto valor agregado ao destino, serão aquelas que poderão estar bem posicionadas no novo contexto. Esta crise brutal exige uma transformação da economia do turismo para superar a alteridade e reconectar os serviços de turismo às necessidades locais (Lapointe, 2020).

\section{Os efeitos do coronavírus nas comunidades: Casos do Brasil e da África}

O atual momento da pandemia de COVID-19 tem sido vivenciado de diferentes formas e intensidades em distintas partes do mundo. O Brasil segue vivendo um drama social, com os números crescentes, enquanto o continente africano vem obtendo melhores resultados (The Lancet, 2020). Durante o processo de coleta de dados e análise de informações para serem publicadas neste artigo, o mundo experimentava números crescentes de contaminação e mortes por COVID-19, atingindo em setembro de 2020, mais de 30 milhões de casos e 1 milhão de mortes (Worldometers, 23/09/2020). Apesar de chocantes, os números continuariam a crescer rapidamente, impulsionados também por flexibilizações nas viagens e pela segunda onda que atingiu fortemente países da Europa e das Américas. No Brasil, após enfrentar meses de alto contágio entre maio e agosto, e relativa queda até novembro, os óbitos voltaram a crescer no primeiro semestre de 2021, retornando a patamares preocupantes. Até à data de submissão da versão final do artigo, os números da COVID-19 no país eram superiores a 18 milhões de infectados, com mais de 500 mil mortes (Worldometers, 23/06/2021).

Embora inicialmente trazida ao país pela elite de férias na Europa, a disseminação do novo coronavírus no Brasil afetou predominantemente os mais pobres, que sofrem com o desabastecimento de água e esgoto e precária assistência médica, revelando desigualdades estruturais (Conde, 2020). São Paulo e Rio de Janeiro foram dois dos estados mais afetados, mas o Amazonas foi um dos primeiros atingidos severamente pela crise, que se espalhou rapidamente pelo interior através das artérias fluviais. A região sudeste do Brasil apresentou situações distintas com relação à disseminação do novo coronavírus. Enquanto o Rio de Janeiro enfrentou altos níveis de contágio desde o início da crise, Minas Gerais conseguiu controlar a propagação da doença por mais tempo, atrasando o crescimento da curva de contágio.

Destes três estados (Amazonas, Minas Gerais e Rio de Janeiro) aparecem os relatos sobre vivências locais, onde as comunidades que trabalham com turismo enfrentaram dificuldades pelo impacto da COVID-19, e lideranças comunitárias vêm se esforçando para superar os desafios sanitários e econômicos. A cidade de Tefé, no interior do Amazonas, entrou em lockdown em março de 2020, e as comunidades das Reservas Mamirauá e Amanã 
enfrentaram dificuldades com as restrições de acesso aos mercados. Nestas duas áreas protegidas, dois projetos de turismo comunitário vivem fases distintas: a consolidada Pousada Uacari (www.uakarilodge.com.br), em Mamirauá e o ainda embrionário modelo da Reserva Amanã. As comunidades Caburini e Vila Alencar estão localizadas nas várzeas do rio Solimões e têm a pesca e o turismo como principais atividades econômicas. Já a comunidade Ubim, localizada nas terras firmes do lago Amanã, tem a agricultura como principal fonte de renda e ainda se organiza para construir um modelo de turismo, que já acontece paulatinamente.

No interior de Minas, o distrito de Conceição de Ibitipoca ainda carrega aspectos rurais associados à pecuária leiteira, mas vive há algumas décadas um constante crescimento devido à proximidade do Parque Estadual do Ibitipoca, onde o turismo é muito presente. A comunidade enfrentou dificuldades pelo fechamento do parque e completa interrupção dos serviços turísticos. Ainda na região sudeste do Brasil, na periferia da cidade do Rio de Janeiro, a comunidade Quilombo Cafundá Astrogilda, situada nas encostas do Parque Estadual da Pedra Branca e que vive uma realidade ao mesmo tempo urbana e rural, também encarou grandes desafios com o fechamento do parque e o encerramento do turismo. Apresenta-se a seguir os relatos de lideranças desses locais, próximos ou no interior das áreas protegidas, com distintas relações com o meio urbano e onde o turismo acontece em diferentes níveis de intensidade. De maneira geral, os lugares pesquisados possuem menor infraestrutura de abastecimento e saneamento e menor presença do Estado e de suas políticas públicas.

D. Martins (julho, 2020), 42 anos, mora na comunidade Caburini, entorno da Reserva Mamirauá (AM) e trabalha há 20 anos na Pousada Uacari. Ela diz que:

A situação foi crítica na região, por falta de estrutura da saúde no interior. Afetou muitas famílias que trabalham na pousada, pois a maioria trabalha só aqui. Quando tivemos que fechar a pousada, muitas famílias deixaram de ganhar seu dinheiro e passaram a trabalhar só na pesca e na agricultura. Vamos voltar a abrir a pousada, mas não vai ser como era antes, vão ter algumas mudanças. É muito difícil pra gente se adaptar, porque estávamos acostumados com uma realidade diferente. O turismo traz um risco, porque os turistas fazem visitas nas comunidades e as pessoas vão ficar com muito medo da transmissão, pois se sentem ameaçadas de que o vírus entre na comunidade. Estamos já nos preparando para a pós-pandemia, não só na pousada, mas também nas comunidades que recebem os visitantes. Vai ser difícil pra receber pessoas de fora, vão ter várias mudanças de procedimentos na pousada, estamos criando os protocolos, para prevenir a saúde dos funcionários e dos hóspedes, com mudança nos passeios de canoa, etc. A gente tem que se adaptar, porque isso não vai passar logo. As pessoas vão estranhar, mas pra gente manter a saúde, vamos ter que seguir os protocolos, adaptando conforme a nossa região, porque cada lugar é diferente. A gente acredita que muitos trabalhadores não vão querer vir trabalhar, com medo da transmissão. Quando eu vi a pousada fechada, deu uma tristeza muito grande, um desanimo, mas estamos aqui, cuidando, pra gente conseguir abrir de novo.

I. Mendonça (julho, 2020), 39 anos, mora na comunidade Vila Alencar, no interior da Reserva Mamirauá (AM), e é condutor local na Pousada Uacari há 18 anos. Ele diz que: 
foi bastante afetada a região, a gente sentiu muito. A situação está mais tranquila agora, mas a gente passou por um período ruim. $O$ coronavírus apareceu na nossa comunidade, mas a gente conseguiu vencer. Teve impacto muito grande na minha vida financeira, é um trabalho que eu gosto muito de fazer, então foi bem ruim ficar sem esse trabalho. A gente está sem informação desde que a pousada foi fechada. A gente não sabe como que vai ficar. O risco que a gente corre através do turismo é de ficar em contato com pessoas estrangeiras e acabar se infectando. A comunidade não recebeu nenhuma ajuda. $O$ plano de retorno a gente não tem, não recebemos informação, sentimos muita falta disso, pois somos a linha de frente do trabalho.

D. Araújo (junho, 2020), 29 anos, mora na comunidade Ubim, interior da Reserva Amanã (AM), e trabalha há dez anos no planejamento do turismo comunitário na região do lago Amanã. Ele diz que:

O coronavírus afetou muito, tanto na cidade como também no interior, dificultou o acesso a alimentação, que ficou mais cara. Os últimos visitantes na Reserva Amanã foram em janeiro de 2020 e não há previsão de voltar os trabalhos com o turismo. No futuro devemos focar no público brasileiro, porque os estrangeiros não vão querer vir tão cedo para o Brasil. O único apoio que as comunidades do lago Amanã receberam foram cestas básicas, que os moradores mesmo reivindicaram. $O$ turismo foi muito afetado na região, e oferece o risco de infectar todos na comunidade.

G. Fortes (julho, 2020), 39 anos, mora na vila de Conceição de Ibitipoca (MG), é condutor ambiental há 25 anos e possui um receptivo turístico (www.sauaturismo.com). Ele diz que:

A vila foi totalmente afetada, porque $80-90 \%$ vive direta ou indiretamente do turismo, que foi um dos segmentos mais afetados. Está tudo parado, agora é tentar entrar nos protocolos de saúde. O turismo oferece um grande risco para a comunidade, que recebe turistas de todo o país e do exterior, principalmente Rio, São Paulo e Belo Horizonte, três capitais muito afetada pela COVID-19. Muitos empreendedores locais são de Juiz de Fora que vem e vão nos finais de semana. Então, o turismo traz esse risco por causa do fluxo grande de pessoas de várias regiões do Brasil. A associação local e empresários criaram planos de apoio e determinação de protocolos que serão levados para a Prefeitura para determinar a reabertura do turismo na região. $O$ grupo de trabalho das comunidades do entorno do parque arrecadou um fundo para conseguir mais dois leitos hospitalares com respiradores para o município.

S. Santos (julho, 2020), 47 anos, mora na cidade do Rio de Janeiro, na comunidade Quilombo Cafundá Astrogilda, localizada nos limites do Parque Estadual da Pedra Branca, onde atua como agente de defesa ambiental. Ele diz que:

A situação da quarentena provocada pela COVID-19 trouxe muita dificuldade para as famílias de nosso território, sem poder sair para trabalhar. O turismo parou por completo, pois estamos localizados dentro de um parque estadual que foi fechado. Meu empreendimento e iniciativa comunitária na parte de turismo está totalmente parado. Turismo nesse momento de pandemia tem um grande risco por causa da aglomeração de pessoas e a possibilidade de trazer o vírus para o nosso território, onde ainda não tem nenhum caso registrado. Não tivemos ajuda por parte do poder público, mas fazemos parte de uma grande rede de ajuda. Para o futuro devemos retornar de forma gradativa, pois ainda não se tem ideia de quando as coisas vão normalizar. 
Destacam-se alguns pontos dos relatos dos moradores, como o desânimo, o desamparo e a falta de renda, o medo de receber turistas e a preparação, envolta em incertezas, para as novas formas de prestar serviços. Modelagens de Tsionas (2020) apontam que a reabertura gradual do setor pode ser viável mesmo com a capacidade reduzida inicialmente a apenas $30 \%$. Hall et al. (2020) acreditam que o turismo em áreas naturais, onde o distanciamento físico pode ser alcançado, será o foco do renascimento inicial do turismo, mas os entrevistados ainda demonstram receio quanto a um possível retorno. Fraser (2020) aponta que o primeiro caso de COVID-19 na Amazônia peruana foi um guia de turismo infectado por visitantes estrangeiros, o que corrobora o medo dos trabalhadores.

Niewiadomski (2020) diz que, pela suspensão de viagens internacionais, os lugares remotos tornaram-se verdadeiramente remotos, e os entrevistados sinalizam como estratégia para a retomada, o turismo de proximidade. Como apontam Sansolo e Bursztyn (2009: 158), "o turismo de base comunitária no Brasil, tem a possibilidade de ser aberto ao próprio Brasil”, mas com o país registrando altos índices de infectados e vítimas fatais, o próprio turismo doméstico continua sendo uma ameaça para as comunidades. Fotiadis el al. (2021) afirmam que o setor deve buscar adotar as orientações médicas, pois representam o caminho mais curto para sair da crise atual.

No continente africano, a passagem da COVID-19 permanece um tanto enigmática, sendo, de acordo com a OMS, a região menos afetada globalmente (The Lancet, 2020). O primeiro caso reportado na África subsaariana foi de um turista italiano que chegou em fevereiro na Nigéria (Lone \& Ahmad, 2020). Os autores alertam que o turismo é o principal setor da economia de países como Quênia, Tanzânia e África do Sul, que sofreram grandes perdas com a paralisação das atividades (Lone \& Ahmad, 2020).

A respeito de exemplos do impacto do coronavírus em projetos de turismo de base comunitária no continente africano, analisa-se um caso na cidade de Maputo, Moçambique, na comunidade de Mafalala, um bairro histórico e com baixos índices de desenvolvimento onde um projeto de turismo comunitário realiza visitas guiadas na área, que conta também com um museu. O outro caso, no interior de Uganda, se refere à uma iniciativa de turismo comunitário às margens do lago Bunyonyi, zona rural da pequena cidade de Kabale, próxima à tríplice fronteira com Ruanda e República Democrática do Congo, região que concentra as áreas protegidas que abrigam os gorilas das montanhas. Ambos os países, Moçambique e Uganda, sofreram com os impactos econômicos, mas apresentaram baixos números de contágio e óbitos, com menos de 100 mil infectados e mil mortes em cada país (Worldometers, 23/06/2021).

I. Laranjeira (junho, 2020), 36 anos, envolvido com atividades culturais e turismo receptivo, coordena há onze anos a associação Iverca de turismo, cultura e meio ambiente (www.iverca.org), no bairro histórico da Mafalala, em Maputo. Ele diz que:

Em Moçambique a pandemia ainda não está com números muito grandes, a situação está minimamente controlada, entretanto a economia do país está parada, estamos a viver um estado de emergência. O turismo é o mais prejudicado, na medida em que as pessoas não podem circular, as fronteiras do país estão fechadas. No nosso caso, nossos serviços eram majoritariamente consumidos por turistas estrangeiros, de origem europeia $e$ norte-americana, que nesse momento não vêm ao país, precisamente por causa da 
COVID e acaba afetando nosso negócio. Na Mafalala, tivemos muitas visitas e reservas canceladas e, daí pra frente, não tivemos mais ninguém. De momento não temos como nos adaptar. Estamos a fazer uso das redes sociais para difundir nosso trabalho, entretanto é muito difícil gerar receita por essa via. Os riscos do turismo são inúmeros na medida em que grande parte dos turistas são estrangeiros, e é precisamente nesses países que a pandemia mais tem afetado e isso contribui para que haja mais riscos. $A$ comunidade não recebeu nenhum tipo de apoio. O que a gente está a planear neste momento é voltar de forma gradual e olhar para um turismo de base doméstica, para o moçambicano que possa manifestar interesse pelo trabalho que a gente faz e ter uma base mais local para promover a nossa iniciativa.

M. Clay (julho, 2020), 33 anos, é guia e coordenador de um empreendimento local no lago Bunyonyi há oito anos, e apoia projetos comunitários (www.hightideandlowtideinternationalrelieffund.org) na região. Ele diz que:

Até agora, em Uganda, não temos tantos casos de COVID-19, mas ainda estamos em espécie de lockdown. Aeroportos, fronteiras e hotéis ainda estão fechados, o turismo não existe mais aqui, há muita recessão e as pessoas estão passando fome. Nessa pandemia foi muito difícil para todos, o governo prometeu nos dar comida e máscaras e eles nunca nos deram. Tudo isso aqui é muito triste. Não sei o que vamos fazer. É uma crise mundial. Tudo está completamente bloqueado. Não sei como vamos acordar dessa recessão. Parques nacionais onde vivem gorilas e chimpanzés ainda estão fechados porque esses primatas podem também se infectar. Visitação aos gorilas está proibida até que haja formas seguras de realizar este tipo de turismo. Eu tenho trabalhado no combate à COVID-19, fazendo máscaras e sabão, tentando procurar apoio.

O impacto da pandemia na realidade africana, em comparação à brasileira, apresenta um quadro melhor na saúde, mas de igual gravidade na questão econômica, em que os entrevistados também reclamam a falta de apoio dos governos. Ainda existe risco de um potencial desastre na África, se os países começarem a relaxar as medidas de isolamento (The Lancet, 2020). Tanto em Maputo, como do interior de Uganda, o desaparecimento dos turistas estrangeiros, compromete muito as economias locais, dependentes desses públicos. Uma combinação de lockdowns, um turismo doméstico incipiente e um mercado destinado a visitantes estrangeiros endinheirados significa que o setor de turismo da África pode não se adaptar rápido o suficiente para evitar o colapso (Nebe, 13/05/2020).

Ambos entrevistados falam sobre buscar outros públicos e parceiros, na tentativa de reduzir a dependência de europeus e estadunidenses. Para Fotiadis et al. (2021), o novo status quo sugere que novos produtos turísticos podem surgir, remodelando o setor. Previsões dos autores sobre a persistência desta crise sugerem que as empresas precisarão reavaliar seus modelos de negócios para incorporar a redução da demanda e aumento de custos (Fotiadis et al., 2021).

No caso de Kabale, o turismo é diretamente associado à visitação de parques nacionais, especificamente para avistar os gorilas das montanhas. Spenceley (23/06/2020) diz que as áreas protegidas estão fechando para visitantes de todo o mundo, a fim de reduzir a propagação do novo coronavírus entre os visitantes e combater a ameaça de transmissão à vida selvagem, citando o caso do turismo com foco nos gorilas em Ruanda, Uganda e República Democrática do Congo. Muitos destinos populares de turismo de grandes primatas já foram fechados como resultado dessa pandemia, arriscando enormes prejuízos para as 
economias locais que dependem dos dólares de conservação fornecidos pelo turismo (Reid, 2020). A situação é de fato crítica como demonstram os estudos preliminares de Santos et al. (2020), que apontam para a possibilidade de primatas serem infectados e desenvolverem sintomas semelhantes aos de seres humanos. Se um novo vírus como o SARS-CoV-2 entrar nas populações de gorilas das montanhas, o impacto poderá ser severo e aumentar a probabilidade de extinção (Mbayahi, 03/07/2020), o que corrobora para a angústia expressada pelo entrevistado, que diz não saber como poderão sair dessa recessão.

\section{Considerações finais}

O turismo é uma atividade sensível a crises sanitárias e econômicas e as populações periféricas que organizam formatos de turismo comunitário, são ainda mais sensíveis a estas questões. Ao mesmo tempo, são estas comunidades que despontam com possibilidade de liderar novos caminhos para uma construção distinta da atividade, em que a relação entre sociedade e ambiente seja mais respeitosa. No entanto, as comunidades mais isoladas (e invisibilizadas) são exatamente as mais negligenciadas pelos poderes públicos. O turismo vai voltar, mas vai levar tempo, permitindo assim que milhares de trabalhadores voltem ao trabalho (Sharfuddin, 2020). Skare et al. (2021) indicam que o renascimento do turismo em todo o mundo exigirá cooperação em vez de competição para minimizar os custos da COVID19.

Em um mundo pós-Covid, uma nova ordem internacional será redesenhada, levando em consideração as lições aprendidas ao lidar com a atual pandemia (Sharfuddin, 2020). Ainda assim, restam muitas perguntas sobre quais serão os caminhos futuros da humanidade, póspandemia. Os seres humanos ficarão mais egoístas e com medo, ou mais solidários e abertos? As comunidades tradicionais e povos indígenas receberão mais atenção e respeito, ou serão ainda mais marginalizadas? O turismo retornará a um modo crescente e exploratório ou buscará formas mais justas e libertadoras? Os desafios enfrentados na pandemia servirão de alerta para os possíveis desafios enfrentados pelas questões climáticas ou por novas pandemias? O ser humano mudará seu curso de existência na Terra para melhor ou para pior? Em um cenário pessimista, poderá o turismo piorar, tornando-se mais excludente, explorador e degradador? Para Sharfuddin (2020) é certo que, quando a pandemia for finalmente controlada e vencida, não haverá como voltar ao mundo tal como era em 2019. Futuras investigações sobre a relação entre turismo e crises globais podem buscar responder a estas perguntas, além de explorar questões como a relação direta entre turismo e propagação de doenças nas comunidades, as melhores práticas comunitárias para evitar o contágio por visitantes, os formatos de turismo que propiciam o distanciamento social, ou os modelos de negócios comunitários que melhor conseguiram enfrentar o período de crise, entre outros.

Buscou-se com este estudo levantar questões sobre distintas realidades em variadas partes do mundo, almejando um panorama mais diversificado sobre os desafios enfrentados, mas certo de apresentar uma análise limitada em quantidade de experiências, coletadas em um tempo e espaços específicos. Espera-se aproveitar dessas análises sobre as vivências locais quanto ao turismo comunitário em tempo de pandemia, para levantar questionamentos que sirvam para refletir sobre as formas de viagens e as relações com as comunidades locais. A partir desse momento de pandemia, novas formas de ser e estar no 
mundo têm sido aclamadas, como uma reflexão sobre as ações destrutivas dos seres humanos no planeta (Brouder, 2020; Galvani et al., 2020; Higgins-Desbiolles, 2020; Lapointe, 2020; Niewiadomski, 2020; Prideaux et al., 2020; Romagosa, 2020; Tremblay-Huet, 2020). Diversas maneiras de aplicação ao turismo têm sido apontadas por estes e outros autores, e o turismo de base comunitária surge como uma possibilidade de valorização de culturas outras, que têm o respeito ao próximo e ao ambiente como base de sua relação com o mundo. Repetindo a conclusão de Grosfoguel (2008: 144) em seus estudos sobre a colonialidade global: talvez seja o momento de, "como dizem os zapatistas, "luchar por un mundo donde otros mundos sean possibles".

\section{Referências}

Bartholo, R., Sansolo, D. \& Bursztyn, I. (2009). Turismo de base comunitária: diversidade de olhares e experiências brasileiras. Letra e Imagem.

Blackstock, K. (2005). A critical look at community-based tourism. Community Development Journal, 40(1), 39-49. https://doi.org/10.1093/cdj/bsioo5

Brouder, P. (2020). Reset redux: possible evolutionary pathways towards the transformation of tourism in a COVID-19 world, Tourism Geographies, 22(3), 484-490. https://doi.org/10.1080/14616688.2020.1760928

Bursztyn, I., Bartholo, R. \& Delamaro, M. (2009). Turismo para quem? Sobre caminhos de desenvolvimento e alternativas para o turismo no Brasil. In R. Bartholo, D. Sansolo \& I. Bursztyn (Orgs.), Turismo de base comunitária: diversidade de olhares e experiências brasileiras (pp. 76-91). Letra e Imagem.

Carr, A. (2020). COVID-19, indigenous peoples and tourism: A view from New Zealand. Tourism Geographies, 22(3), 491-502. https://doi.org/10.1080/14616688.2020.1768433

Chinazzi, M., Davis, J., Ajelli, M., Gioannini, C., Litvinova, M., Merler, S. Piontti, A., Mu, K., Rossi, L., Sun, K., Viboud, C., Xiong, X., Yu, H., Halloran, E., Longini, I. \& Vespignani, A. (2020). The effect of travel restrictions on the spread of the 2019 novel coronavirus (COVID-19) outbreak. Science, 368, 395400. https://doi.org/10.1126/science.aba9757

Coelho, E. (2013). Refletindo sobre turismo de base comunitária em Unidades de Conservação através de uma perspectiva amazônica. Revista Brasileira de Ecoturismo, 6(1), 313-326. https://doi.org/10.34024/rbecotur.2013.v6.6181

Conde, M. (2020). Brazil in the Time of Coronavirus. Geopolítica(s): Revista de Estudios sobre Espacioo y Poder, 11 (número especial), 239-249. https://doi.org/10.5209/geop.69349

Coriolano, L. (2009). O turismo comunitário no nordeste brasileiro. In R. Bartholo, D. Sansolo \& I. Bursztyn (Orgs.), Turismo de base comunitária: Diversidade de olhares e experiências brasileiras (pp. 277-288). Letra e Imagem.

Fotiadis, A., Polyzos, S. \& Huan, T.C. (2021). The good, the bad and the ugly on COVID-19 tourism recovery. Annals of Tourism Research, 87, 1-14. https://doi.org/10.1016/j.annals.2020.103117

Fraser, B. (2020). COVID-19 strains remote regions of Peru. The Lancet - World Report. 395 (May 30), 1684. https://doi.org/10.1016/S0140-6736(20)31236-8

Galvani, A., Lew, A. \& Perez, M. (2020). COVID-19 is expanding global consciousness and the sustainability of travel and tourism, Tourism Geographies, 22(3), 567-576. https://doi.org/10.1080/14616688.2020.1760924

Gössling, S., Scott, D. \& Hall, C. (2021). Pandemics, tourism and global change: A rapid assessment of COVID-19, Journal of Sustainable Tourism, 29(19), 1-20. https://doi.org/10.1080/09669582.2020.1758708

Grosfoguel, R. (2008). Para descolonizar os estudos de economia política e os estudos pós-coloniais: Transmodernidade, pensamento de fronteira e colonialidade global. Revista Crítica de Ciências Sociais, 80, 115-147. https://doi.org/10.4000/rccs.697

Hall, C., Scott, D. \& Gössling, S. (2020). Pandemics, transformations and tourism: Be careful what you wish for, Tourism Geographies, 22(3), 577-598. https://doi.org/10.1080/14616688.2020.1759131

Higgins-Desbiolles, F. (2020). Socialising tourism for social and ecological justice after COVID-19, Tourism Geographies, 22(3), 610-623. https://doi.org/10.1080/14616688.2020.1757748 
Hoque, A., Shikha, F.; Hasanat, M., Arif, I., Bakar, A. \& Hamid, A. (2020). The effect of Coronavirus (COVID-19) in the tourism industry in China. Asian Journal of Multidisciplinary Studies, 3(1), 52-58.

Irving, M (2009). Reinventando a reflexão sobre turismo de base comunitária: inovar é possível? In R. Bartholo, D. Sansolo \& I. Bursztyn (Orgs.), Turismo de base comunitária: diversidade de olhares e experiências brasileiras (pp. 108-121). Letra e Imagem.

Kiss, A. (2004). Is community-based ecotourism a good use of biodiversity conservation funds? TRENDS in Ecology and Evolution, 19(5), 232-237. https://doi.org/10.1016/j.tree.2004.03.010

Lapointe, D. (2020). Reconnecting tourism after COVID-19: the paradox of alterity in tourism areas, Tourism Geographies, 22(3), 633-638. https://doi.org/10.1080/14616688.2020.1762115

Lew, A., Cheer, J., Haywood, M., Brouder, P. \& Salazar, N. (2020). Visions of travel and tourism after the global COVID-19 transformation of 2020, Tourism Geographies, 22(3), 455-466. https://doi.org/10.1080/14616688.2020.1770326

Lima, I. \& D'Hauteserre, A. (2011). Ecotourism, social and human capitals, and identity valorization: The communities of Tapajós (PA), Brazil. Revista Brasileira de Ecoturismo, 4(2), 250-273. https://doi.org/10.34024/rbecotur.2011.v4.5916

Linka, K., Peirlinck, M., Costabal, F. \& Kuhl, E. (2020). Outbreak dynamics of COVID-19 in Europe and the effect of travel restrictions. Computer Methods in Biomechanics and Biomedical Engineering, 23(11), 710-717. https://doi.org/10.1080/10255842.2020.1759560

Lone, S. A. \& Ahmad, A. (2020). COVID-19 pandemic - an African perspective. Emerging Microbes \& Infections, 9(1), 1300-1308. https://doi.org/10.1080/22221751.2020.1775132

Maldonado, C. (2009). O turismo rural comunitário na América Latina: gênesis, características e políticas In R. Bartholo, D. Sansolo \& I. Bursztyn (Orgs.), Turismo de base comunitária: diversidade de olhares e experiências brasileiras (pp. 25-44). Letra e Imagem.

Mbayahi, A. (2020, 03 julho). Mountain Gorilla tourism in the wake of COVID-19: How close should we get? IGCP.

Mendonça, T. \& Irving, M. (2004). Turismo de base comunitária: a participação como prática no desenvolvimento de projetos turístico no Brasil - Prainha Do Canto Verde, Beberibe (CE). Caderno Virtual de Turismo, 4(4), 12-22.

Nebe, C. (2020, 13 maio). How COVID-19 is destroying Africa's tourism industry. Deutsche Welle.

Niewiadomski, P. (2020). COVID-19: From temporary de-globalisation to a rediscovery of tourism?, Tourism Geographies, 22(3), 651-656. https://doi.org/10.1080/14616688.2020.1757749

Nunes, J. (2020). A pandemia de COVID-19: Securitização, crise neoliberal e a vulnerabilização global. Caderno de Saúde Pública, 36(5), 1-4. https://doi.org/10.1590/0102-311x00063120

Okazaki, E. (2008). A Community-Based Tourism Model: Its Conception and Use. Journal of Sustainable Tourism, 16(5), 511-529. https://doi.org/10.1080/09669580802159594

OMT [Organização Mundial do Turismo] (2020). Barómetro OMT del Turismo Mundial: mayo 2020 - Con especial enfoque en el impacto de la COVID-19 (resumen).

Peralta, N. (2008). Impactos do ecoturismo sobre a agricultura familiar na Reserva de Desenvolvimento Sustentável Mamirauá, AM. UAKARI, 4(1), 29-40.

Prideaux, B., Thompson, M. \& Pabel, A. (2020). Lessons from COVID-19 can prepare global tourism for the economic transformation needed to combat climate change, Tourism Geographies, 22(3), 667678. https://doi.org/10.1080/14616688.2020.1762117

Reid, M. (2020). Is 2020 the year when primatologists should cancel fieldwork? American Journal of Primatology, 82(8). https://doi.org/10.1002/ajp.23161

Romagosa, F. (2020). The COVID-19 crisis: Opportunities for sustainable and proximity tourism, Tourism Geographies, 22(3), 690-694. https://doi.org/10.1080/14616688.2020.1763447

Salazar, N. (2012). Community-based cultural tourism: issues, threats and opportunities. Journal of Sustainable Tourism, 20(1), 9-22. https://doi.org/10.1080/09669582.2011.596279

Sampaio, C. \& Coriolano, L. (2009). Dialogando com experiências vivenciadas em Marraquech e América Latina para compreensão do turismo comunitário e solidário. Revista Brasileira de Pesquisa em Turismo, 3(1), 4-24.

Sánchez, M. (2020). Flujos turísticos, geopolítica y COVID-19: Cuando los turistas internacionales son vectores de transmisión. Geopolítica(s), 11 (número especial), 105-114. https://doi.org/10.5209/geop.69249 
Sansolo, D. \& Bursztyn, I. (2009). Turismo de base comunitária: potencialidade no espaço rural brasileiro. In R. Bartholo, D. Sansolo \& I. Bursztyn (Orgs.), Turismo de base comunitária: diversidade de olhares e experiências brasileiras (pp. 142-161). Letra e Imagem.

Santos, W., Guiraldi, L. \& Lucheis, S. (2020). Should we be concerned about COVID-19 with nonhuman primates? American Journal of Primatology, 82(8), 1-3. https://doi.org/10.1002/ajp.23158

Sausmarez, N. (2007). Crisis management, tourism and sustainability: The role of indicators. Journal of Sustainable Tourism, 15(6), 700-714. https://doi.org/10.2167/jost653.0

Sharfuddin, S. (2020). The world after Covid-19, The Round Table, 109(3), $247-257$. https://doi.org/10.1080/00358533.2020.1760498

Skare, M., Soriano, D. \& Porada-Rocho, M. (2021). Impact of COVID-19 on the travel and tourism industry. Technological Forecasting \& Social Change, 163, 1-14. https://doi.org/10.1016/j.techfore.2020.120469

Spenceley, A. (2020, 23 junho). COVID-19 and tourism in Africa's protected areas: Impacts and recovery needs. Enhanced Integrated Framework. Trade for Development News.

Stronza, A., Durham, W. (2008). Ecotourism and conservation in the Americas. CAB International.

Strydom, A., Mangope, D. \& Henama, U. (2018). Lessons learned from successful community-based tourism case studies from the global South. African Journal of Hospitality, Tourism and Leisure, $7(5), 1-13$.

Strydom, A., Mangope, D. \& Henama, U. (2019). A critique of the interface between tourism, sustainable development and sustainable tourism in community-based tourism theory. African Journal of Hospitality, Tourism and Leisure, 8(5), 1-12.

The Lancet (2020). Editorial - COVID-19 in Africa: no room for complacency. The Lancet, 395(10238), 1669. https://doi.org/10.1016/S0140-6736(20)31237-X

Tremblay-Huet, S. (2020). COVID-19 leads to a new context for the "right to tourism": a reset of tourists' perspectives on space appropriation is needed, Tourism Geographies, 22(3), 720-723. https://doi.org/10.1080/14616688.2020.1759136

Tsionas, M. (2020). COVID-19 and gradual adjustment in the tourism, hospitality, and related industries. Tourism Economics, 1-5. https://doi.org/10.1177/1354816620933039

Wen, J., Wang, W., Kozak, M., Liu, X. \& Hou, H. (2020). Many brains are better than one: The importance of interdisciplinary studies on COVID-19 in and beyond tourism. Tourism Recreation Research, 46(2), 300-313. https://doi.org/10.1080/02508281.2020.1761120

Worldometers. Coronavirus https://www.worldometers.info/coronavirus/

Yang, Y., Zhang, H. \& Chen, X. (2020). Coronavirus pandemic and tourism: Dynamic stochastic general equilibrium modeling of infectious disease outbreak. Annals of Tourism Research, 1-6. https://doi.org/10.1016/j.annals.2020.102913

EdUARDO DE ÁVILA COELHo é turismólogo, mestre em turismo e meio ambiente, e atualmente desenvolve pesquisa de doutorado em geografia pela Universidade Federal de Minas Gerais, onde investiga sobre as formas comunitárias de organização para o turismo em áreas protegidas da Amazônia brasileira e das savanas da Tanzânia. Endereço institucional: Instituto de Geociências, Avenida Antônio Carlos, 6.627, Pampulha, CEP 31270-901, Belo Horizonte, Minas Gerais, Brasil.

Submetido em 22 de janeiro 2021

Aceite em 25 de junho 2021 